\title{
Hybrid Carrier Frequency Modulation Based on Rotor Position to Reduce Sideband Vibro-acoustics in PMSM Used by Electric Vehicle
}

\author{
Zizhen Qiu ${ }^{1}$, Yong Chen ${ }^{1}$, Xiaozhe Lin ${ }^{2}$, Haiquan Cheng ${ }^{1}$, Yang Kang ${ }^{1}$, Xu Liu ${ }^{3}$ \\ 1 Tianjin Key Laboratory of Power Transmission and Safety Technology for New Energy Vehicles, Hebei \\ University of Technology, Tianjin 300130, China. \\ qiuziz92@163.com; CHQ9633@163.com; kangyang1125@163.com. \\ 2 Zhejiang Geely Automobile Co., Ltd. \\ joelin@geely.com. \\ 3 State Key Laboratory of Reliability and Intelligence of Electrical Equipment, Hebei University of Technol- \\ ogy, Tianjin 300130, China. \\ liuxu@hebut.edu.cn.

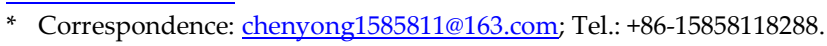

\begin{abstract}
In the permanent magnet synchronous motor (PMSM) drive system, the unwilling and ear-piercing vibro-acoustics caused by high-frequency sideband harmonics becomes unacceptable in the electric vehicle application. In this paper, a modified space vector pulse-width modulation (SVPWM) technique implemented with hybrid carrier frequency modulation (HCFM) is provided to reduce the sideband current harmonic components and vibro-acoustic responses. The principle and implementation of the proposed HCFM technique are firstly presented, in which the fixed carrier frequency is improved with the sawtooth and random signal-based coupling modulation based on the rotor position. For verification, the experiment tests are carried out on a prototype 12/10 PMSM and microcontroller unit. The effectiveness of the HCFM technique can hence be confirmed, in which the sideband vibro-acoustics reduction shows more effectively than that in conventional random PWM. The proposed approach may provide a new route in noise-cancelling and electromagnetic compatibility for the electric drive powertrain.
\end{abstract}

Keywords: permanent magnet synchronous motor, sideband harmonic component; space vector pulse-width modulation; carrier frequency modulation; vibro-acoustic responses.

This paper is a selected paper from the 34th International Electric Vehicles Symposium and Exhibition (Nanjin, China), paper ID: 2170299.

\section{Introduction}

In recent years, permanent magnet synchronous motor (PMSM) driven with pulsewidth modulation (PWM) techniques have widely used in electric vehicles (EVs) and hybrid electric vehicles (HEVs) Error! Reference source not found.. The high-frequency vibro-acoustics responses introduced by sideband voltage/current harmonics are mainly located and contributed around the carrier frequency and its multiples, which brings much more noise, vibration and harshness $(\mathrm{NVH})$ challenges during the design and optimization stages of the vehicle platform Error! Reference source not found..

Which has been confirmed that electromagnetic vibro-acoustics is the most significant contributor to the PMSM system due to electromagnetic forces on the stator and rotor caused by air-gap magnetic fields, such as the cogging torque Error! Reference source not found., torque ripple Error! Reference source not found. and the high-frequency sideband vibro-acoustics Error! Reference source not found.. In contrast to the previous two types, the sideband vibro-acoustics is related to the control unit, associated with the 
voltage source inverter (VSI), and also to the pulse-width modulation (PWM) technique. The fixed carrier frequency causes the current harmonic components to contribute around the carrier frequency and its multiples Error! Reference source not found.. With the interaction between the permanent magnet (PM) field and the armature reaction field, the ear-piercing vibro-acoustic responses can thus be produced Error! Reference source not found.

In order to reduce the sideband components, some effective methods have been presented [10-14]. The most representative method is called the harmonics spread spectra (HSS) technique, such as periodic signal-based dithering modulation Error! Reference source not found. and random pulse-width modulation (RPWM) Error! Reference source not found.. The periodic dithering modulation transfers the fixed carrier frequency to the determined periodic ways, such as sawtooth, sinusoidal, and square Error! Reference source not found.. Ditto for RPWM, the carrier frequency would be randomly distributed within a defined range Error! Reference source not found.. However, the related singleHSS technique would exhibit saturating and limiting effect such that the sideband components cannot be further reduced Error! Reference source not found., even other negative influences, increasing the total harmonic distortion (THD) Error! Reference source not found. and electromagnetic interference (EMI) Error! Reference source not found., on the power converter system.

Therefore, this paper presents a novel hybrid carrier frequency modulation (HCFM) method to modify the conventional space vector pulse-width modulation (SVPWM) technique, in which the fixed carrier frequency can be dithered by coupling the sawtooth and random signal-based patterns with different rotor position angles. The corresponding experimental tests are presented with great practical significance to verify the proposed HCFM technique.

The paper is organized into five sections. Following this introduction, the principle and implementation of the HCFM technique are presented in Section II, where the explanation of sideband harmonics reduction is also proposed. The experimental setup is presented in Section III. Then, the results are obtained in Section IV. Finally, the conclusion is summarized in Section V.

\section{Hybrid Carrier Frequency Modulation}

\subsection{Principle and Implementation of the HCFM}

The implementation of the conventional SVPWM is shown in Figure 1 and Figure 2. Taking Sector I for an example, the output PWM signals, q-axes voltages and q-axes current are shown in Figure 3. With the d-q voltage calculated models, harmonic analysis can be developed with quantitative analysis of the q-axes voltage, which can be confirmed that the sideband harmonic components are related to the time duration of the zero-vectors $T_{0}$ and $T_{7}$. Moreover, the time durations are also related to the rotor position Error! Reference source not found.. Hence, the hybrid carrier frequency modulation is based on the rotor position to combine the corresponding periodic and random signal-based dithering methods, which can be seen in Figure 4.

As shown in Figure 4, the carrier frequency in this work is set at $8000 \mathrm{~Hz}$. The periodic signal, associated with a sawtooth form, is employed, as while the regular random signal is also employed. The dithering range is set as $1000 \mathrm{~Hz}$, which means the modified carrier frequency is distributed between $7000 \mathrm{~Hz}$ and $9000 \mathrm{~Hz}$. Changing with the rotating angles of the rotor, the carrier frequency dithers per 30 degrees, in which the triangle waves of the carrier frequency are also simply presented. 


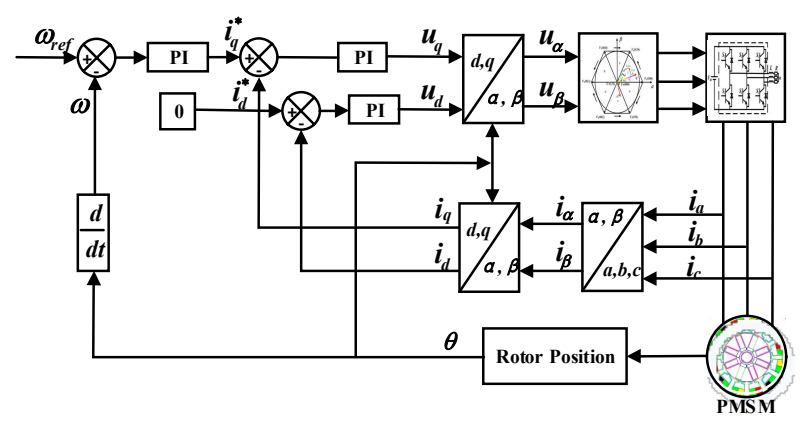

Figure 1. Implementation of control system.

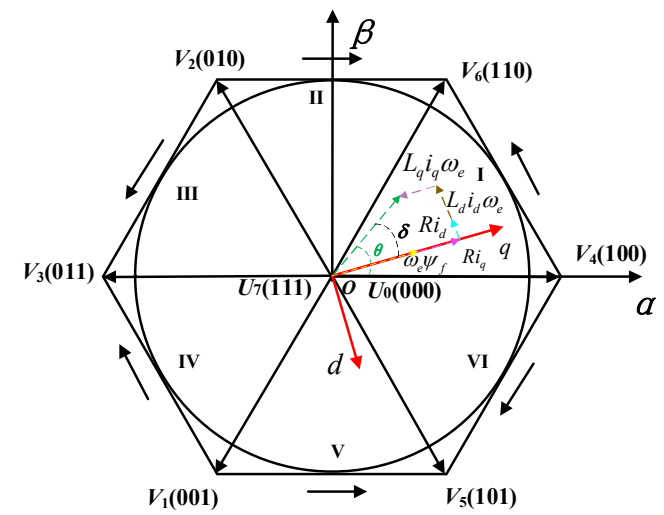

Figure 2. Principle of conventional SVPWM.

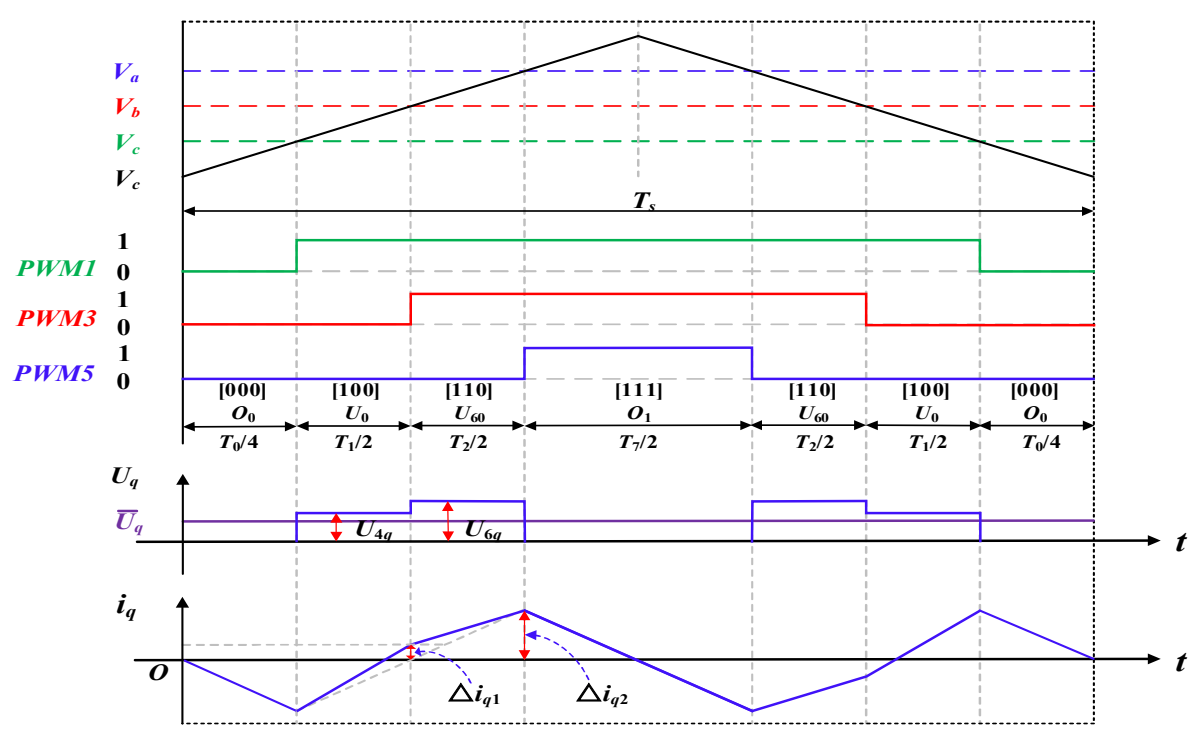

Figure 3. Pattern of SVPWM in Sector I and q-axis current ripple. 


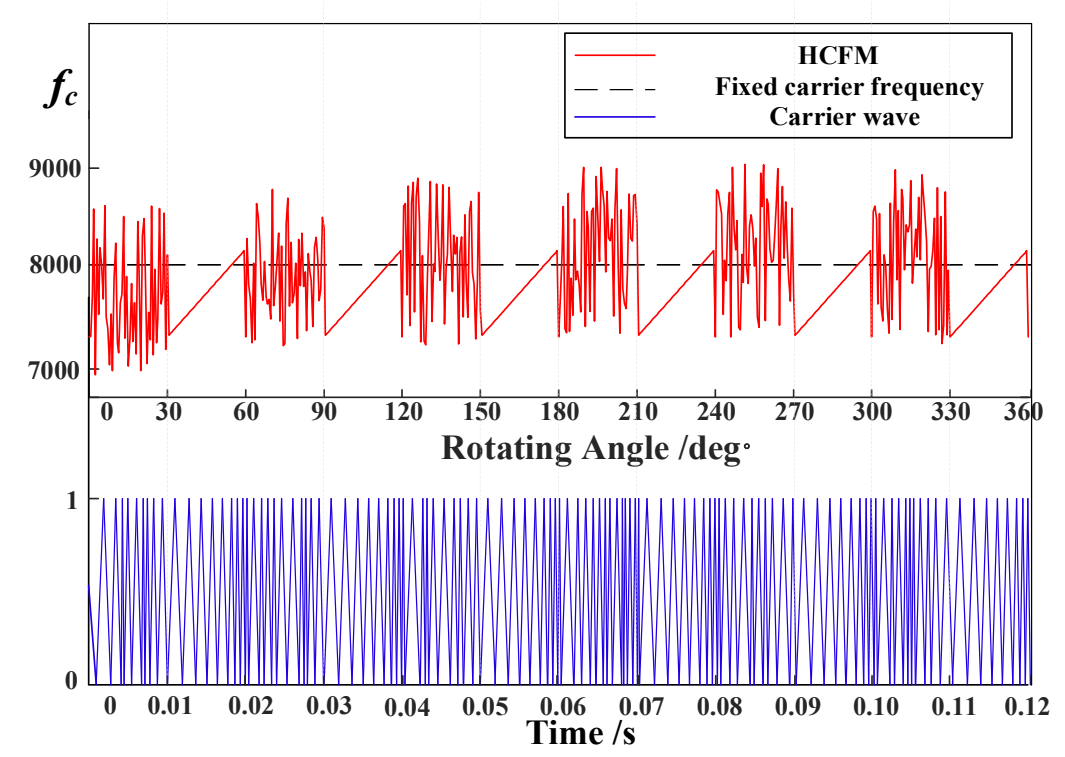

Figure 4. The variation laws and the corresponding carrier waves of carrier frequency with HCFM.

\subsection{Explanation of Sideband Harmonics Reduction}

The analysis of the sideband harmonics can be proposed by the quantitative analysis of q-axis voltages. Neglecting the stator resistance, the working angle in the steady-state can be expressed as $\delta$. Acting with $U_{4}$ and $U_{6}$ separately, $U_{q}$ can be expressed respectively as Error! Reference source not found.

$$
\begin{gathered}
U_{4 q}=\frac{2}{3} U_{d c} \cos (\theta-\delta) \\
U_{6 q}=\frac{2}{3} U_{d c} \cos \left(\delta-\theta+60^{\circ}\right) \\
\vec{U}_{q}=\frac{T_{4}}{T_{s}} \vec{U}_{4 q}+\frac{T_{6}}{T_{s}} \vec{U}_{6 q}
\end{gathered}
$$

where, $T_{4}$ and $T_{6}$ can be expressed by using the phase voltage amplitude $U_{m}$ and the vector clamping angle $\theta$.

$$
\begin{gathered}
T_{4}=\sqrt{3} \frac{U_{m}}{U_{d c}} T_{s} \sin \left(60^{\circ}-\theta\right) \\
T_{6}=\sqrt{3} \frac{U_{m}}{U_{d c}} T_{s} \sin \theta \\
T_{0}=T_{s}-T_{4}-T_{6} \\
=T_{s}\left[1-\frac{\sqrt{3} U_{m}}{U_{d c}} \cos \left(\theta-30^{\circ}\right)\right]
\end{gathered}
$$

With (1), (2) and (6), the phase wave in one period can be obtained in Figure 3. Then, the first and second orders of current harmonics, $\Delta i_{q 1}$ and $\Delta i_{q 2}$, can be presented as 


$$
\begin{gathered}
\Delta i_{q 1} \approx \frac{U_{m} T_{s} \cdot\left[\sin \left(60^{\circ}+\delta\right)-\sin \frac{\delta}{2}\right]}{4 \sqrt{3} L_{q}} \\
\Delta i_{q 2} \approx \frac{U_{q} T_{s}}{4 L_{q}} \cdot\left[1-\frac{\sqrt{3} U_{m}}{2 U_{d c}}\right]
\end{gathered}
$$

It can be seen from (7) and (8) that the second order of current harmonics mainly affects q-axis current harmonic components. Moreover, the magnitude of $\Delta i_{q}$ is determined by $T_{0}, L_{q}$ and $U_{q}$. In this study, the $T_{0}$ can thus be optimized by the rotor position to reduce the sideband harmonics. The optimized configuration can be shown in Figure 4 and expressed as

$$
f_{s}=\left\{\begin{array}{lc}
f_{t 1}+R_{i} \Delta f & {\left[\frac{k \pi}{6}<\theta<\frac{(k+1) \pi}{6}\right]} \\
f_{c}+f_{t 2} \Delta f & {\left[\frac{(k+1) \pi}{6}<\theta<\frac{(k+2) \pi}{6}\right]}
\end{array}\right.
$$

In (9), $f_{c}$ is the carrier frequency. $\Delta f$ is the dithering index defining the harmonics spread range, which sets $1000 \mathrm{~Hz}$ in this study. $f_{t 1}$ is the frequency of the sinusoidal wave. $f_{t 2}$ is the frequency of sawtooth wave meeting as $[-1,1]$. $R_{i}$ is the random modulation index. According to the above analysis, the novel HCFM based on rotor position not only reduces harmonic currents but also achieves a wider spectrum extension.

\section{Experimental Test Setup}

As shown in Figure 5 and Figure 6, the test bench, set up by prototype PMSM, powerdriven system, and measurements, is presented to verify the effectiveness of the proposed HCFM technique. The prototype 12/10 PMSM is adopted to the rear axle driven unit in an EV application, whose parameters can be found in Table 1 . The DC power is fed by $540 \mathrm{~V}-$ $4.5 \mathrm{kw}$. Three full-bridge power modules are employed by circuit boards with InfineonBSM75GB120DN2. Based on the dSPACE-MicroLabBox 1103, serval PWM strategies can be established with MATLAB/Simulink and RTI Electric Motor Control Blockset. The corresponding pulse signals can be generated and controlled online.

The vibro-acoustic tests are measured by ICP triaxial accelerometer with a sensitivity of $50 \mathrm{mV} / \mathrm{g}$ and a sound-pressure microphone (GRAS-46AE) with the sensitivity of $47.23 \mathrm{mV} / \mathrm{Pa}$. The phase current signals are recorded by Teletronix-A622 current probe and processed by Tektronix TDS2024c.

The operational condition of all experimental tests is set at $1000 \mathrm{r} / \mathrm{min}$ and $4 \mathrm{Nm}$, in order to obtain the sideband current harmonics and vibro-acoustic responses obviously. Based on the setting rotating speed $1000 \mathrm{r} / \mathrm{min}$, the rotation frequency and fundamental frequency are $16.67 \mathrm{~Hz}$ and $83.34 \mathrm{~Hz}$, respectively.

Table 1. Parameters of prototype PMSM

\begin{tabular}{cccc}
\hline Item & Value & Item & Value \\
\hline Number of slots & 12 & Type of controller & VSI \\
Number of poles & 10 & Carrier frequency & $8000 \mathrm{~Hz}$ \\
Rated speed & $2000 \mathrm{r} / \mathrm{min}$ & DC link voltage & $540 \mathrm{~V}$ \\
Rated torque & $8 \mathrm{Nm}$ & Rated power & $1.8 \mathrm{~kW}$ \\
\hline
\end{tabular}




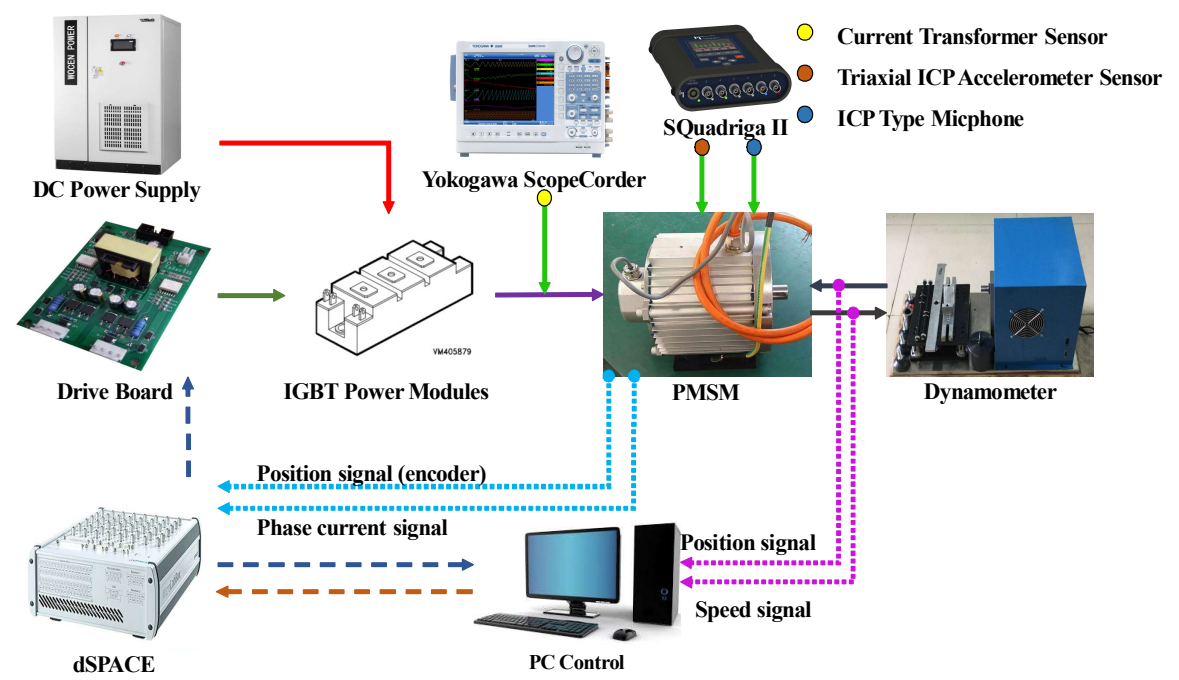

Figure 5. Overview of the test platform.

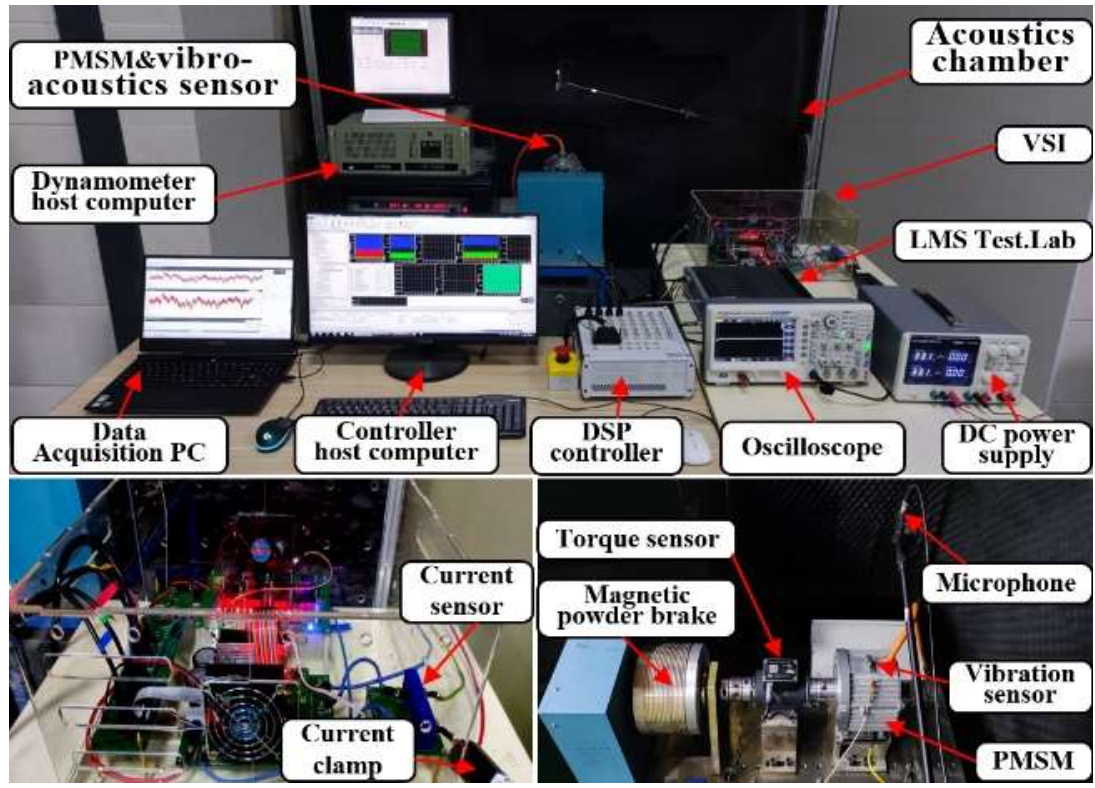

Figure 6. Experimental setup with the PMSM and instrumentation

\section{Results and Discussions}

\subsection{Sideband Current Harmonics}

The experimental results of sideband current harmonics are shown in Figure 7, in which the comparison among the conventional SVPWM, RPWM and HCFM techniques is presented by the power spectrum density (PSD). The sideband components in conventional SVPWM obtain a specific pattern in that two symmetric sidebands appear around the first carrier frequency. The sidebands at $f_{c} \pm 2 f_{0}$ and $f_{c} \pm 4 f_{0}$, where $f_{0}$ is the fundamental frequency of the electrical supply, which can be calculated by the rotation frequency $f_{r}$, i.e., $f_{r}=n / 60$ and $f_{0}=p \cdot f_{r}$, Considering that $f_{0}$ is $83.34 \mathrm{~Hz}$ under $1000 \mathrm{r} / \mathrm{min}$, the main sidebands can be obtained with four main orders, where the peak magnitude is $-27.56 \mathrm{~dB} / \mathrm{Hz}$.

With the RPWM and HCFM, the current harmonic reduction can be seen in Figures 8and Figure 9. Different from the conventional SVPWM, the obvious orders are disappeared. The concentrated harmonics are extended to the specified frequency domain with a $1000 \mathrm{~Hz}$ dithering range as the setting. The peak magnitude in RPWM is $-39.56 \mathrm{~dB} / \mathrm{Hz}$, 
while $-48.78 \mathrm{~dB} / \mathrm{Hz}$ or even below in HCFM. The reduction effort in the proposed HCFM is more significant than that in RPWM.

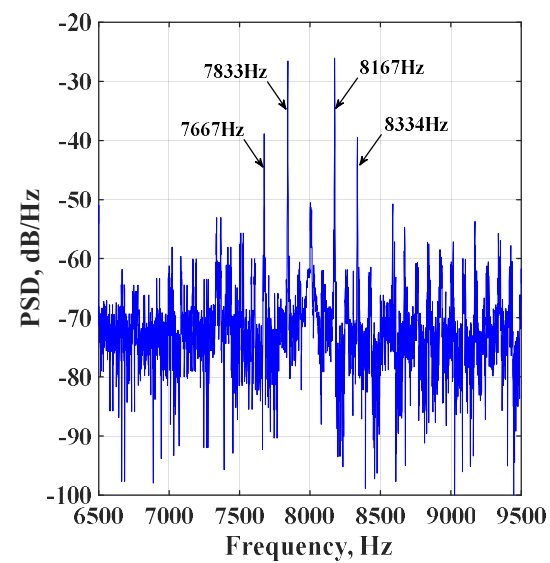

Figure 7. The sideband current harmonics with conventional SVPWM

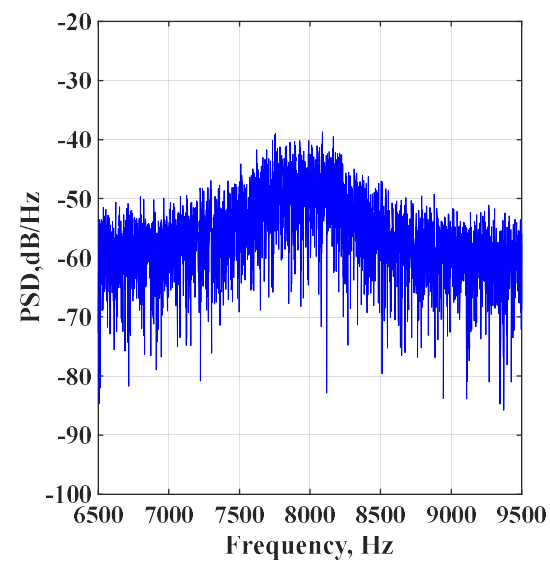

Figure 8. The sideband current harmonics with random PWM

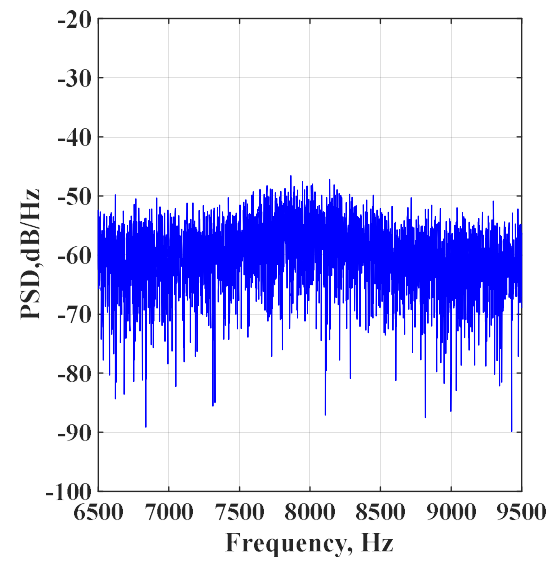

Figure 9. The sideband current harmonics with HCFM

\subsection{Sideband Vibro-acoustic Responses}

The experimental vibro-acoustics results are carried out to the frequency domain. The comparison of the sideband vibro-acoustic responses is shown in this chapter. As shown in the following Figures, the vibro-acoustic responses obtain a significant correlation with the current harmonics. In Figure 10, the sideband orders of the conventional SVPWM in vibro-acoustic responses are located with $f_{c \pm} \pm f_{0}, f_{c} \pm 3 f_{0}$, and $f_{c} \pm 5 f_{0}$. 


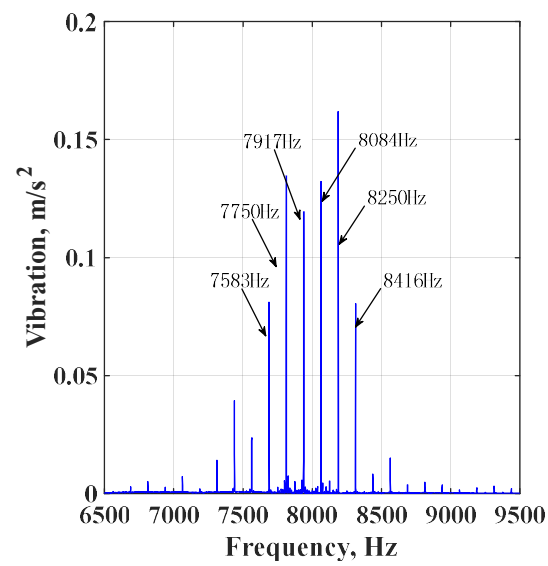

(a) vibration

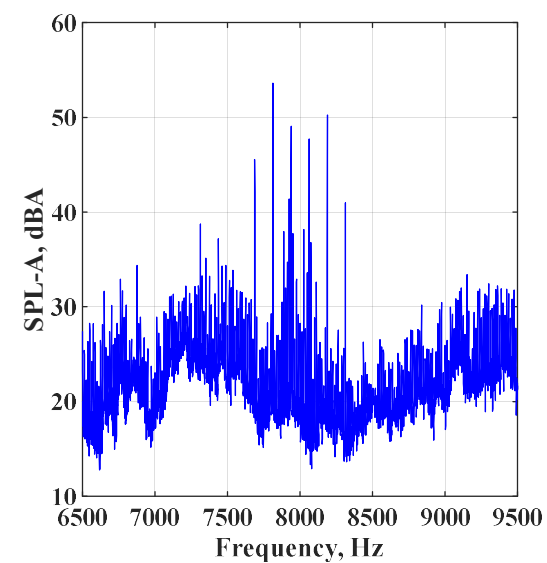

(b) acoustic noise

Figure 10. The sideband vibro-acoustic responses with conventional SVPWM

With the reduction techniques in Figure 11 and Figure 12, the relatively concentrated sideband components are spread to a wider frequency band, which has been cut off at lower and upper frequencies $7000 \mathrm{~Hz}$ and $9000 \mathrm{~Hz}$. The original narrow-band acoustics are reduced below $50 \mathrm{dBA}$, even below $40 \mathrm{dBA}$ by using HCFM.

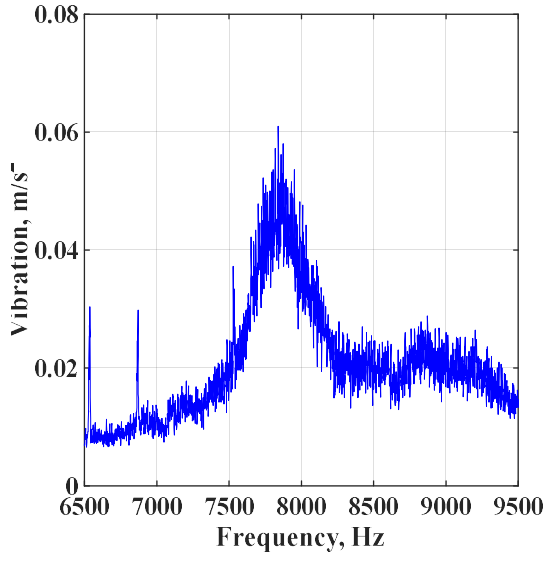

(a) vibration

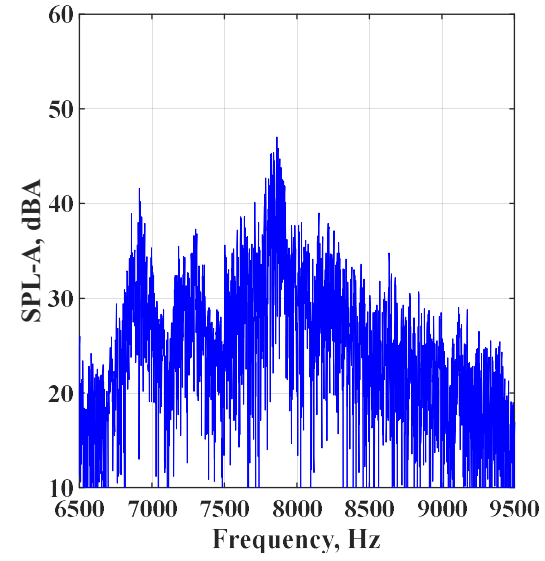

(b) acoustic noise

Figure 11. The sideband vibro-acoustic responses with random PWM

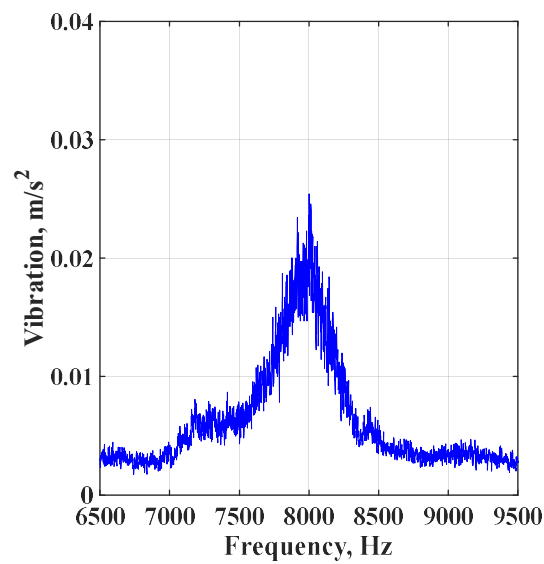

(a) vibration

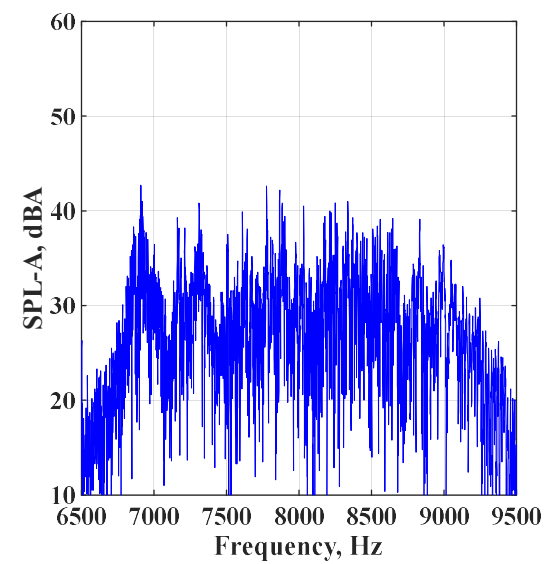

(b) acoustic noise

Figure 12. The sideband vibro-acoustic responses with HCFM

\section{Conclusions}


In this paper, a novel PWM technique applied with hybrid carrier frequency modulation is proposed to reduce the sideband harmonics and vibro-acoustics. The proposed HCFM technique is implemented by the rotor position, in which sawtooth and random signal-based dithering methods are combined to achieve the hybrid carrier waves modulation. With the experimental tests, the magnitude of sideband current harmonics can be reduced by about $20 \mathrm{~dB} / \mathrm{Hz}$, resulting in a $0.12 \mathrm{~m} / \mathrm{s}^{2}$ vibration reduction and $10 \mathrm{dBA}$ acoustic noise reduction. The reduction efforts in HCFM are more significant than those in RPWM. The results can provide a reference for multi-strategies control to achieve further vibro-acoustics and EMI reduction in EV application.

Author Contributions: All authors contributed to this work. Conceptualization, Zizhen Qiu., Formal analysis, Haiquan Cheng, Investigation, Zizhen Qiu, Yong Chen and Xu Liu, Methodology, Zizhen Qiu and Haiquan Cheng, Validation, Zizhen Qiu and Yang Kang, Writing - original draft, Zizhen Qiu, Writing - review and editing, Yong Chen and Xu Liu., Funding acquisition, Xiaozhe Lin.

Funding: This work was supported by the Ningbo Science and Technology Project (Grant No. 2019B10111), Hebei Province full-time introduction of high-end talent projects (NO. 20181228), Hebei Subsidized Project of Innovative Ability Training for Postgraduates (Grant No. CXZZBS2021033) and China Scholarship Council (Grant No. 201906700001).

Conflicts of Interest: The authors declare no conflict of interest.

\section{References}

References must be numbered in order of appearance in the text (including citations in tables and legends) and listed individually at the end of the manuscript. We recommend preparing the references with a bibliography software package, such as EndNote, ReferenceManager or Zotero to avoid typing mistakes and duplicated references. Include the digital object identifier (DOI) for all references where available.

Citations and references in the Supplementary Materials are permitted provided that they also appear in the reference list here.

In the text, reference numbers should be placed in square brackets [ ] and placed before the punctuation; for example [1], [1-3] or $[1,3]$. For embedded citations in the text with pagination, use both parentheses and brackets to indicate the reference number and page numbers; for example [5] (p. 10), or [6] (pp. 101-105).

1. Momen, F. , Rahman K, Son Y, et al. . Electrical propulsion system design of Chevrolet Bolt battery electric vehicle. 2016 IEEE Energy Conversion Congress and Exposition (ECCE), IEEE, 2017.

2. Zhi, Y. , Fei S , Member S, et al. . Comparative Study of Interior Permanent Magnet, Induction, and Switched Reluctance Motor Drives for EV and HEV Applications. IEEE Transactions on Transportation Electrification, 2015, 1(3), pp. 245-254.

3. M. A. Hannan, F. A. Azidin, and A. Mohamed. Hybrid electric vehicles and their challenges: A review. Renewable and Sustainable Energy Reviews, 2019, 29, pp. 135-150.

4. Fang, Y. , and T. Zhang. Sound Quality of the Acoustic Noise Radiated by PWM-fed Electric Powertrain. IEEE Transactions on Industrial Electronics, 2018, 65, pp.4534-4541.

5. Wu L J , Zhu Z Q , Staton D A, et al. Comparison of Analytical Models of Cogging Torque in Surface-Mounted PM Machines. XIX International Conference on Electrical Machines, IEEE, 2010, pp.1-6.

6. Fei, W., and Z. Q. Zhu.Comparison of Cogging Torque Reduction in Permanent Magnet Brushless Machines by Conventional and Herringbone Skewing Techniques. IEEE Transactions on Energy Conversion, 2013, 3(28), pp.664-674.

7. Z. Qiu, Y. Chen, et al. Analysis of the sideband current harmonics and vibro-acoustics in the PMSM with SVPWM, IET Power Electronics, 2020, 13, pp. 1033-1040.

8. W. Liang, P. C. Luk and W. Fei, Analytical Investigation of Sideband Electromagnetic Vibration in Integral-Slot PMSM Drive with SVPWM Technique, IEEE Transactions on Power Electronics,2016, 32(6), pp.4785-4795.

9. W. Liang, W. Fei and P. C. Luk, An Improved Sideband Current Harmonic Model of Interior PMSM Drive by Considering Magnetic Saturation and Cross-Coupling Effects, IEEE Transactions on Industrial Electronics, 2016, 63(7), pp.4097-4104.

10. Z. Qiu, Y. Kang, Y. Chen, X. Liu and F. Gu. Investigation into Periodic Signal-based Dithering Modulations for Suppression Sideband Vibro-acoustics in PMSM Used by Electric Vehicles, IEEE Transactions on Energy Conversion, 2021, 1, pp.1-1. (Early Access).

11. Y. L. Huang, Y. X. Xu, et al. Hybrid periodic carrier frequency modulation technique based on modified SVPWM to reduce the PWM noise, IET Power Electronics, 2019, 12, pp.515-520.

12. Y. L. Huang, Y. X. Xu, et al. PWM Frequency Voltage Noise Cancelation in Three-Phase VSI Using the Novel SVPWM Strategy, IEEE Transactions on Power Electronics, 2018, 33(10), pp.8596-8606. 
13. Y. Xu, Y. Yao, Q. Yuan, J. Zou and J. Shang. Reduction of the acoustic noise in PMSM drives by the periodic frequency modulation, 2011 International Conference on Electrical Machines and Systems, Beijing, China, 2011, pp.1-5.

14. A. Ruiz-Gonzalez, M. Meco-Gutierrez, et al. Pulse width modulation technique with harmonic injection in the modulating wave and discontinuous frequency modulation for the carrier wave to reduce vibrations in asynchronous machines, IET Power Electronics, 2019, 12, pp.2865-2872.

15. R. M. Pindoriya, B. S. Rajpurohit and R. Kumar. A Novel Application of Harmonics Spread Spectrum Technique for Acoustic Noise and Vibration Reduction of PMSM Drive, IEEE Access, 2020, 8, pp.103273-103284.

16. W. Zhang, Y. Xu, J. Ren, J. Su and J. Zou. Synchronous random switching frequency modulation technique based on the carrier phase shift to reduce the PWM noise, IET Power Electronics, 2020, 13, pp.892-897.

17. G. Wang, B. Zheng and Y. Xu. A Novel SVPWM Strategy for High-Frequency Noise Suppression of Dual Three-phase PMSM, PCIM Asia 2018; International Exhibition and Conference for Power Electronics, Intelligent Motion, Renewable Energy and Energy Management, Shanghai, China, 2018, pp.1-4.

18. K. Chen and Y. Xie. Multiphase optimal injection PWM with dual carrier frequency to reduce current THD, IET Power Electronics, 2017, 10, pp.1061-1076.

19. K. Lee, G. Shen, W. Yao and Z. Lu. Performance Characterization of Random Pulse Width Modulation Algorithms in Industrial and Commercial Adjustable-Speed Drives, IEEE Transactions on Industrial Applications, 2017, 53, pp.1078-1087.

20. W. Deng and S. Zuo. Comparative Study of Sideband Electromagnetic Force in Internal and External Rotor PMSMs With SVPWM Technique, IEEE Transactions on Industrial Electronics, 2016, 2(66), pp.956-966. 